\title{
One-step synthesis of polydispersed silver nanocrystals using Malva sylvestris: an eco-friendly mosquito larvicide with negligible impact on non-target aquatic organisms
}

\author{
Marimuthu Govindarajan $^{1}$ • S. L. Hoti $^{2} \cdot$ Mohan Rajeswary $^{1} \cdot$ Giovanni Benelli $^{3}$
}

Received: 14 January 2016 / Accepted: 14 March 2016 / Published online: 14 April 2016

(C) Springer-Verlag Berlin Heidelberg 2016

\begin{abstract}
The synthesis of eco-friendly nanoparticles is evergreen branch of nanoscience with a growing number of biomedical implications. In this study, we investigated the synthesis of polydisperse and stable silver nanoparticles (AgNP) using a cheap leaf extract of Malva sylvestris (Malvaceae). Bio-reduced AgNP were characterized by UV-visible spectrophotometry, Fourier transform infrared spectroscopy (FTIR), $\mathrm{X}$-ray diffraction analysis (XRD), atomic force microscopy (AFM), scanning electron microscopy (SEM) and transmission electron microscopy (TEM). The acute toxicity of M. sylvestris leaf extract and green-synthesized AgNP was evaluated against larvae of the malaria vector Anopheles stephensi, the dengue vector Aedes aegypti and the filariasis vector Culex quinquefasciatus. Compared to the leaf aqueous extract, AgNP showed higher toxicity against $A$. stephensi, $A$. aegypti, and $C$. quinquefasciatus with $\mathrm{LC}_{50}$ values of $10.33,11.23$, and $12.19 \mu \mathrm{g} / \mathrm{mL}$, respectively. Greensynthesized AgNP were found safer to non-target organisms Diplonychus indicus and Gambusia affinis, with respective $\mathrm{LC}_{50}$ values ranging from 813.16 to $1044.52 \mu \mathrm{g} / \mathrm{mL}$. Overall, this research firstly shed light on the mosquitocidal potential of M. sylvestris, a potential bio-resource for rapid,
\end{abstract}

Marimuthu Govindarajan

drgovindzoo@yahoo.com

Giovanni Benelli

g.benelli@sssup.it; benelli.giovanni@gmail.com

1 Unit of Vector Control, Phytochemistry and Nanotechnology, Department of Zoology, Annamalai University, Annamalainagar 608 002, Tamil Nadu, India

2 Regional Medical Research Centre, Nehru Nagar, Belgaum 590010, Karnataka, India

3 Department of Agriculture, Food and Environment, University of Pisa, via del Borghetto 80, 56124 Pisa, Italy cheap and effective synthesis of polydisperse and highly stable silver nanocrystals.

Keywords Biosafety $\cdot$ Biosynthesis $\cdot$ Mosquito-borne diseases $\cdot$ Nanotechnology $\cdot$ Zika virus

\section{Introduction}

Nanotechnology is a developing interdisciplinary field of research interspersing material science, bionanoscience, and technology. Remarkable advances are made in the field of biotechnology and nanotechnology to harness the benefit of life sciences, health care, and industrial biotechnology (Gardea-Torresdey et al. 2002; Lee et al. 2003; Benelli 2016; Murugan et al. 2016a, b, c). A reliable and eco-friendly process for synthesis of metallic nanoparticles is an important step in the field of nanotechnology. Many materials are synthesized in nano-size for various applications including medicine, engineering, biomedical electronics, and pest management (Kalimuthu et al. 2008; Smitha et al. 2008). Metals are commonly used for the synthesis of nanoparticles relying to chemical and biological methods. However, chemical methods usually involve use of highly toxic chemicals for synthesis of nanoparticles, which makes them certainly unsuitable for a number of purposes of public health importance. An alternative, eco-friendly, and advantageous approach to chemical methods is the biological nanosynthesis (Benelli 2016).

Recently, biological synthesis of silver nanoparticles has received a special attention due to its cheap and eco-friendly features. Current research shows that rapid green synthesis of metal nanoparticles can be easily performed using metabolites from bacteria, fungi, and plants. In particular, plant-mediated synthesis has been successfully applied for the production of silver nanoparticles, due to its faster rate of synthesis and also 
the possibility to reduce the steps in downstream processing (Huang et al. 2007; Salam et al. 2012).

Mosquitoes (Diptera: Culicidae) are vectors of high public health importance. Anopheles stephensi, Aedes aegypti, and Culex quinquefasciatus are vectors of many pathogens and parasites accounting for huge mortality and morbidity worldwide, including malaria, dengue, Zika virus, Japanese encephalitis and filariasis (Benelli and Mehlhorn 2016; Benelli et al. 2016). The better strategy to lower the incidence of mosquitotransmitted diseases is to avoid mosquito biting using skin repellents, insecticide-treated bed nets, and targeting mosquito young instars with pesticides (Benelli 2015a). In larval stage, mosquitoes have less mobility in breeding habitat, so devising control measures at this stage is comparatively easy (Howard et al. 2007). Current practice aimed to the control of mosquito larvae mainly relies to the use of synthetic pesticides carbamates, organophosphates, and pyrethroids. In the early days of their use, insecticides showed success in reducing vector population, but the frequent and blind use of insecticides increases selection pressure on mosquitoes creating resistance and also had negative impact on human health and non-target species (Raghvendra 2002; Sarwar et al. 2009). In view of these facts, plant-borne control tools can be considered a safer and effective alternative (Benelli 2015b; Pavela 2015a, b).

Nowadays, a growing number of plants are screened successfully for nanosynthesis of silver nanoparticles (AgNP), including Sida acuta (Veerekumar et al. 2013), Barleria cristata (Govindarajan and Benelli 2015), Chomelia asiatica (Muthukumaran et al. 2015a), Gmelina asiatica (Muthukumaran et al. 2015b), Feronia elephantum (Veerakumar et al. 2014a), and Heliotropium indicum (Veerakumar et al. 2014b). Phyto-synthesized silver nanoparticles (AgNP) have been recently proposed as effective mosquito larvicides and are gaining importance over synthetic chemical pesticides because of their reduced harmful effects to non-target species and novelty in the mechanism(s) of action (Patil et al. 2012a; Benelli 2016).

Malva sylvestris (Malvaceae), also known as common mallow, is an herb widely present in India, growing to a height of $4 \mathrm{ft}$. In traditional medicine, the most commonly used parts of the plant are flowers and leaves without petiole. The active ingredients include mucilage, tannins, malvyn, and malvidin (Tomoda et al. 1989). The plant leaves are also rich in nutraceuticals such as antioxidants (phenols, flavonoids, carotenoids, and tocopherols), unsaturated fatty acids (e.g., $\alpha$-linolenic acid), and minerals (Barros et al. 2010). The anti-inflammatory, antimicrobial, and antioxidant activities of this plant have been documented by many studies (Billeter et al. 1991; Pirbalouti et al. 2010). However, its mosquitocidal activity is currently unknown.

In this research, we proposed a cheap and rapid method of synthesis of polydispersed AgNP using the aqueous leaf extract of $M$. sylvestris. Bio-reduced AgNP were characterized by UV-Vis spectrophotometry, Fourier transform infrared spectroscopy (FTIR), X-ray diffraction analysis (XRD), atomic force microscopy (AFM), scanning electron microscopy (SEM), and transmission electron microscopy (TEM). The acute toxicity of $M$. sylvestris leaf extract and greensynthesized AgNP was evaluated against the larvae of malaria vector $A$. stephensi, the dengue vector $A$. aegypti, and the filariasis vector $C$. quinquefasciatus. Furthermore, we evaluated the biotoxicity of $M$. sylvestris aqueous extract and greensynthesized AgNP on three non-target aquatic organisms sharing the same ecological niche of Anopheles and Aedes mosquitoes, Diplonychus indicus, and Gambusia affinis.

\section{Materials and methods}

\section{Materials}

Silver nitrate was procured from Merck, India. The glassware was acid-washed thoroughly and then rinsed with Millipore Milli-Q water. Healthy and fresh leaves of $M$. sylvestris were collected from Nilgiris, Western Ghats $\left(11^{\circ} 10^{\prime} \mathrm{N}\right.$ to $11^{\circ} 45^{\prime} \mathrm{N}$ latitude and $76^{\circ} 14^{\prime} \mathrm{E}$ to $77^{\circ} 2^{\prime} \mathrm{E}$ longitude), Tamil Nadu State, India. The identity was confirmed at the Department of Botany, Annamalai University, Annamalai Nagar, Tamil Nadu. Voucher specimens were numbered and kept in our laboratory and are available upon request.

\section{Preparation of plant extracts}

Leaves of M. sylvestris were dried in the shade and ground to fine powder in an electric grinder. Aqueous extract was prepared by mixing $50 \mathrm{~g}$ of dried leaf powder with $500 \mathrm{~mL}$ of water (boiled and cooled distilled water) with constant stirring on a magnetic stirrer. The suspension of dried leaf powder in water was left for $3 \mathrm{~h}$ and filtered through Whatman $\mathrm{n} .1$ filter paper, and the aqueous filtrate were stored in an ambercolored airtight bottle at $10{ }^{\circ} \mathrm{C}$ temperature until testing.

\section{Synthesis of silver nanoparticles}

Ten grams of thoroughly washed and finely cut leaves were added in a $300-\mathrm{mL}$ Erlenmeyer flask along with $100 \mathrm{~mL}$ of sterilized double-distilled water, and the mixture was boiled for $5 \mathrm{~min}$ before finally decanting it. The colloidal extract was filtered with Whatman filter paper no. 1 , stored at $-15{ }^{\circ} \mathrm{C}$, and tested within a week. The filtrate was treated with aqueous $1 \mathrm{mM} \mathrm{AgNO}(21.2 \mathrm{mg}$ of $\mathrm{AgNO}_{3}$ powder in $125 \mathrm{~mL}$ of Milli-Q water) solution in an Erlenmeyer flask and incubated at room temperature. Eighty-eight milliliters of an aqueous solution of $1 \mathrm{mM}$ silver nitrate was reduced using $12 \mathrm{~mL}$ of leaf extract at room temperature for $10 \mathrm{~min}$, resulting in a brown-yellow solution indicating the formation of AgNP. 


\section{Characterization of synthesized silver nanoparticles}

The bioreduction of $\mathrm{Ag}^{+}$ions was monitored using a UV-Vis spectrophotometer (UV-160v, Shimadzu, Japan). Analysis on size, morphology, agglomeration pattern, and dispersed nature of AgNP was performed by atomic force microscopy (Agilent Technologies AFM- 5500), scanning electron microscopy (Hitachi S3000 H SEM), and transmission electron microscopy (TEM Technite 10 Philips). The purified AgNP were examined for the presence of biomolecules using FTIR spectroscopy (Thermo Scientific Nicolet 380 FT-IR Spectrometer) $\mathrm{KBr}$ pellets, and crystalline AgNP were determined by XRD analysis.

\section{Mosquito rearing}

Following the method by Govindarajan and Benelli (2015), laboratory-bred pathogen-free strains of mosquitoes were reared in the vector control laboratory, Department of Zoology, Annamalai University. At the time of adult feeding, these mosquitoes were 3-4 days old after emergences (maintained on raisins and water) and were starved for $12 \mathrm{~h}$ before feeding. Each time, 500 mosquitoes per cage were fed on blood using a feeding unit fitted with Parafilm as membrane for $4 \mathrm{~h}$. A. aegypti feeding was done from 12 noon to 4:00 p.m. and $A$. stephensi and $C$. quinquefasciatus were fed during 6:00 to 10:00 p.m. A membrane feeder with the bottom end fitted with Parafilm was placed with $2.0 \mathrm{~mL}$ of the blood sample (obtained from a slaughter house by collecting in a heparinized vial and stored at $4{ }^{\circ} \mathrm{C}$ ) and kept over a netted cage of mosquitoes. The blood was stirred continuously using an automated stirring device, and a constant temperature of $37^{\circ} \mathrm{C}$ was maintained using a water jacket circulating system. After feeding, the fully engorged females were separated and maintained on raisins. Mosquitoes were held at $28 \pm 2{ }^{\circ} \mathrm{C}, 70-85 \%$ relative humidity, with a photoperiod of $12-\mathrm{h}$ light and $12-\mathrm{h}$ dark.

\section{Acute toxicity against mosquito larvae}

Larvicidal activity of the aqueous crude extract and AgNP from M. sylvestris was evaluated according to World Health Organization (2005). The aqueous extract was tested at 70, 140, 210, 280, and $350 \mu \mathrm{g} \mathrm{mL}^{-1}$ concentrations, and AgNP was tested at 5, 10, 15, 20, and $25 \mu \mathrm{g} \mathrm{mL} \mathrm{m}^{-1}$ concentrations. Twenty numbers of late III instar larvae were introduced into a $500-\mathrm{mL}$ glass beaker containing $250 \mathrm{~mL}$ of dechlorinated water, plus the desired concentrations of leaf extract or AgNP. For each concentration, five replicates were performed. Larval mortality was recorded at $24 \mathrm{~h}$ after exposure, during which no food was given to the larvae. Each test included a set control groups (silver nitrate and distilled water) with five replicates for each individual concentration.

\section{Biotoxicity on non-target organisms}

The effect of non-target organisms was assessed following the method by Sivagnaname and Kalyanasundaram (2004). The effect of aqueous extract and AgNP was tested against non-target organisms $D$. indicus and G. affinis. The species were field collected and separately maintained in cement tanks $(85-\mathrm{cm}$ diameter and 30$\mathrm{cm}$ depth) containing water at $27 \pm 3{ }^{\circ} \mathrm{C}$ and relative humidity $85 \%$.

The aqueous extract and AgNP of M. sylvestris was evaluated at concentrations of 50 times higher the $\mathrm{LC}_{50}$ dose for mosquito larvae. Ten replicates will be performed for each concentration along with four replicates of untreated controls. The non-target organisms were observed for mortality and other abnormalities such as sluggishness and reduced swimming activity after 48-h exposure. The exposed non-target organisms were also
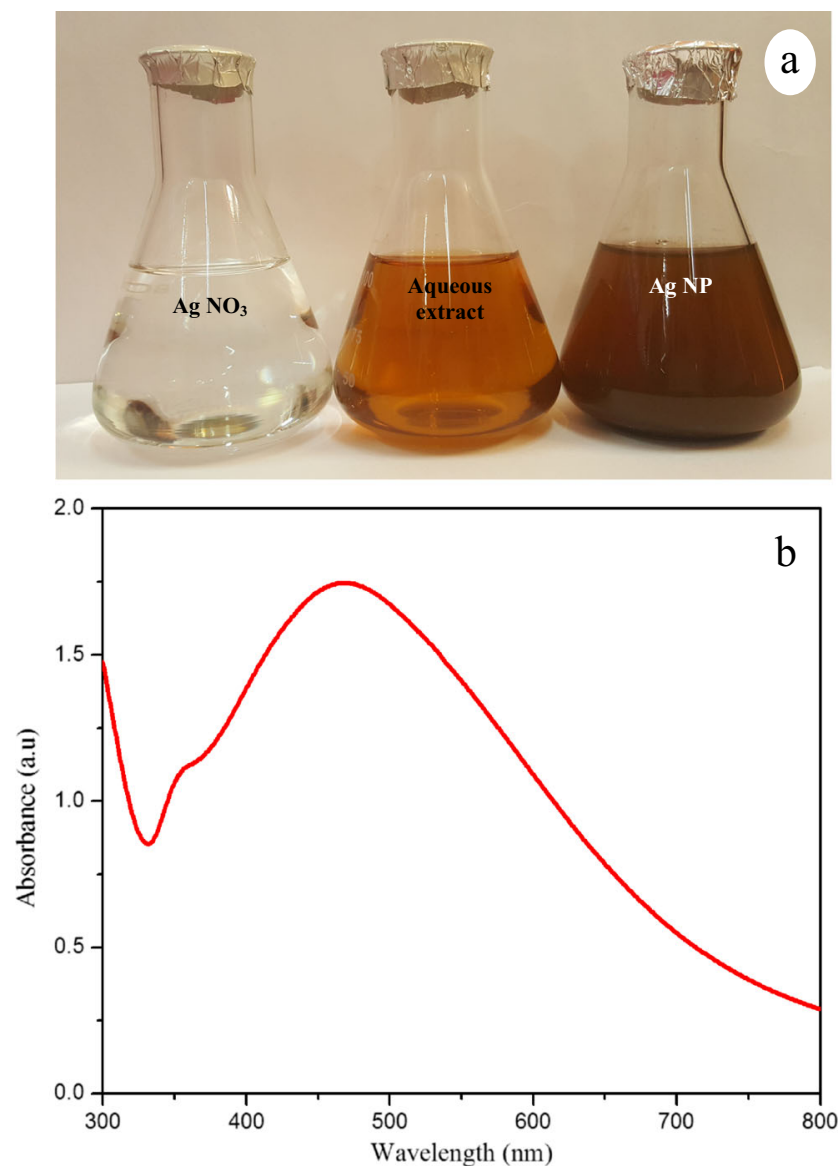

Fig. 1 a Color intensity of Malva sylvestris aqueous extract before and after the reduction of silver nitrate $(1 \mathrm{mM})$. The color change indicates $\mathrm{Ag}^{+}$reduction to elemental nanosilver. b UV-visible spectrum of silver nanoparticles after $180 \mathrm{~min}$ from the reaction 


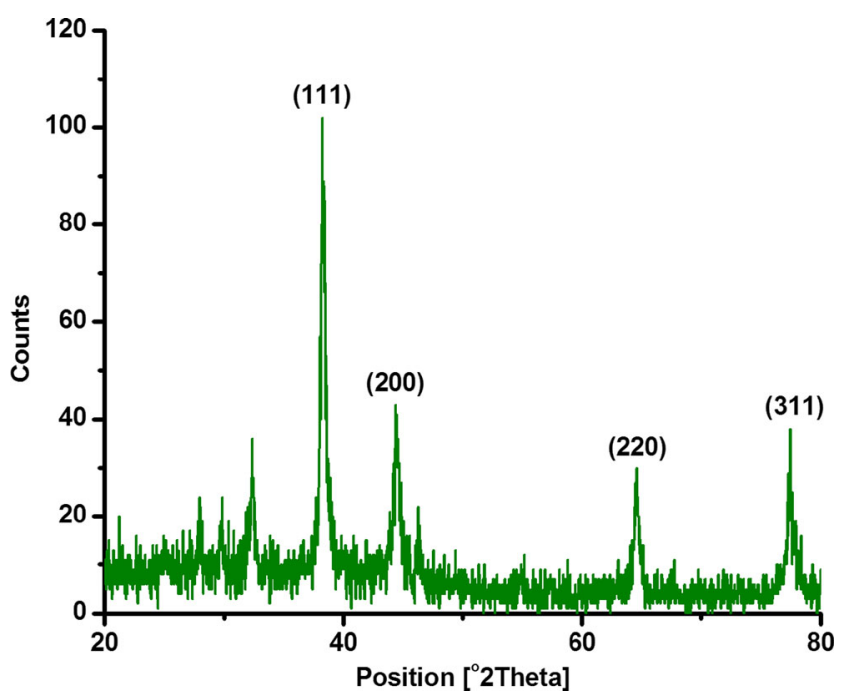

Fig. 2 XRD pattern of silver nanoparticles synthesized using the Malva sylvestris aqueous extract

observed continuously for 10 days to understand the post-treatment effect of this extract on survival and swimming activity.

\section{Data analysis}

Mortality data were subjected to probit analysis. $\mathrm{LC}_{50}$ and LC $_{90}$ were calculated using the method by Finney (1971). In experiments evaluating biotoxicity on non-target organisms, the Suitability Index (SI) was calculated for each non-target species using the following formula (Deo et al. 1988).

$\mathrm{SI}=\frac{\mathrm{LC}_{50} \text { of non-target organisms }}{\mathrm{LC}_{50} \text { of target vector species }}$

All data were analyzed using the SPSS Statistical Software Package version 16.0. A probability level of $P<0.05$ was used for the significance of differences between values.

\section{Results and discussion}

\section{Biosynthesis and characterization of silver nanoparticles}

After incubation with silver nitrate in dark room, the pale yellow colloidal solution turned into a dark brown suspension, which indicated AgNP synthesis (Fig. 1a). M. sylvestris-

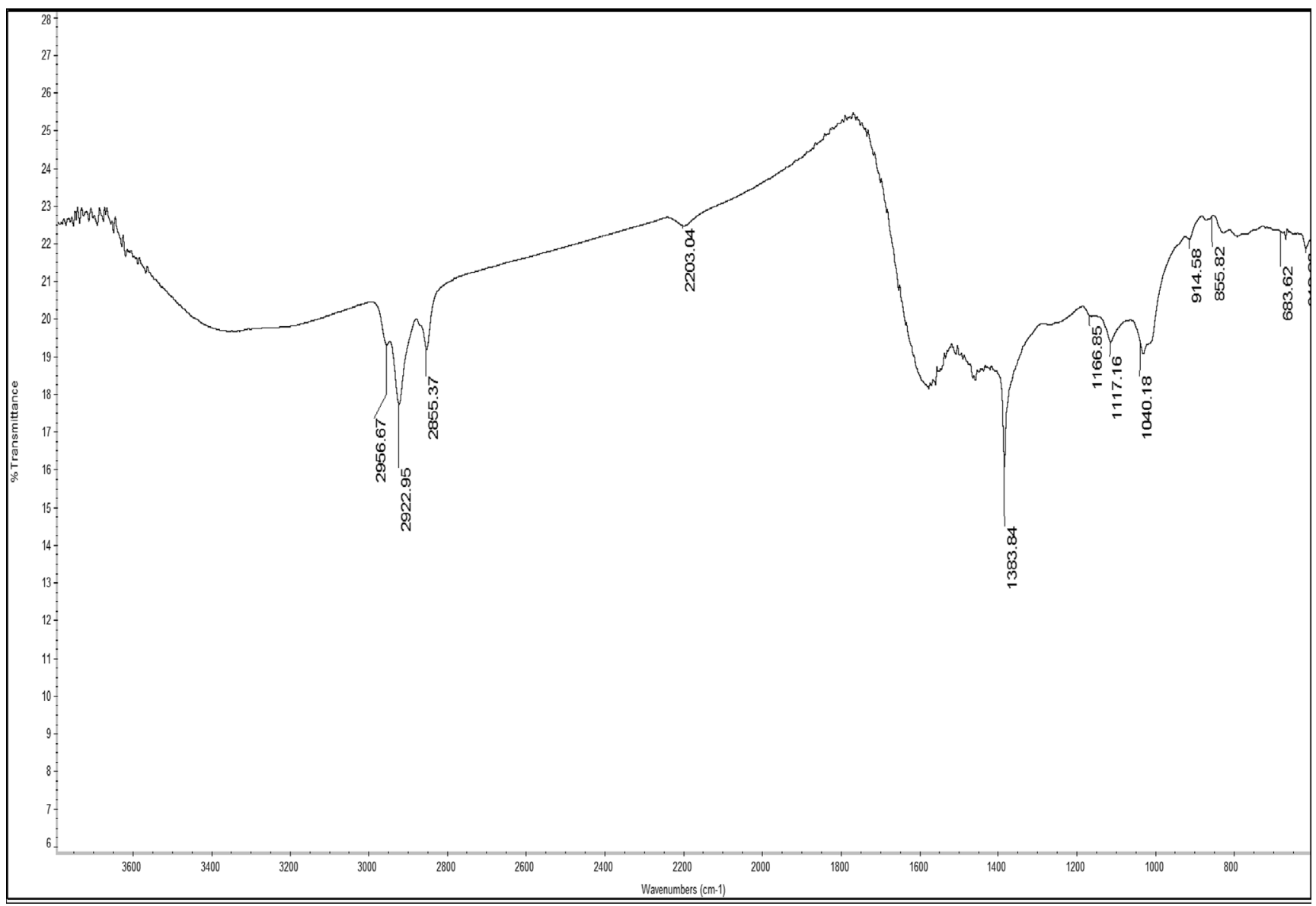

Fig. 3 FTIR spectrum of silver nanoparticles synthesized using the Malva sylvestris aqueous leaf extract 
$\mathbf{a}$

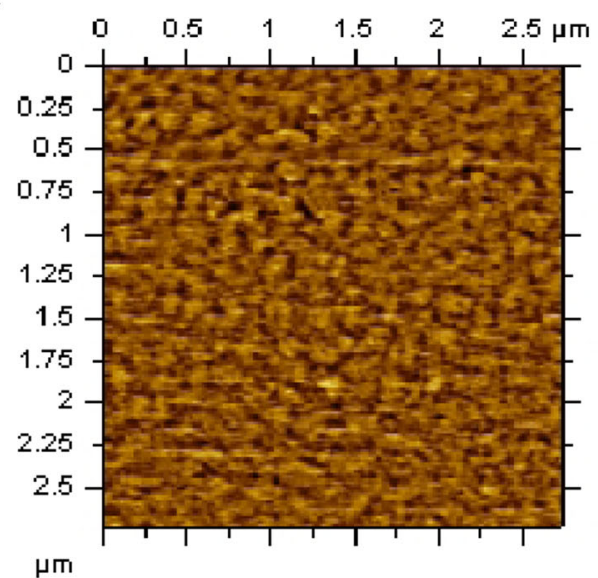

$\mathrm{nm}$

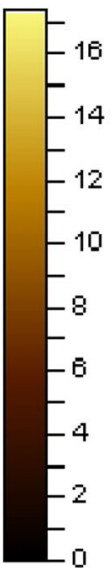

c

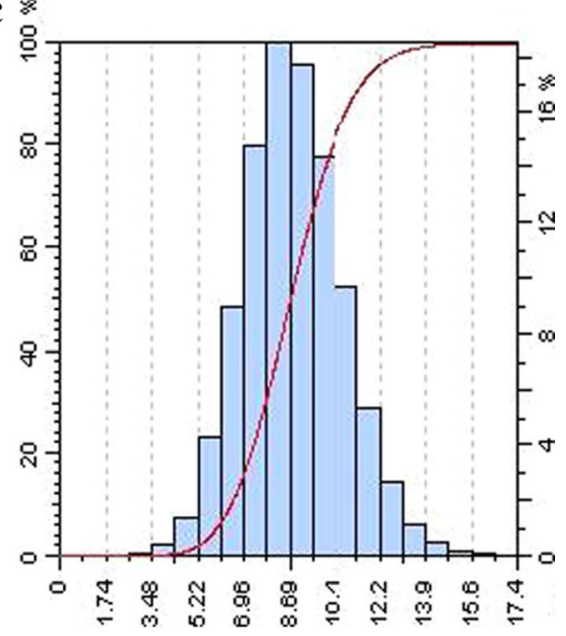

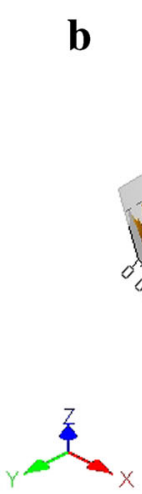

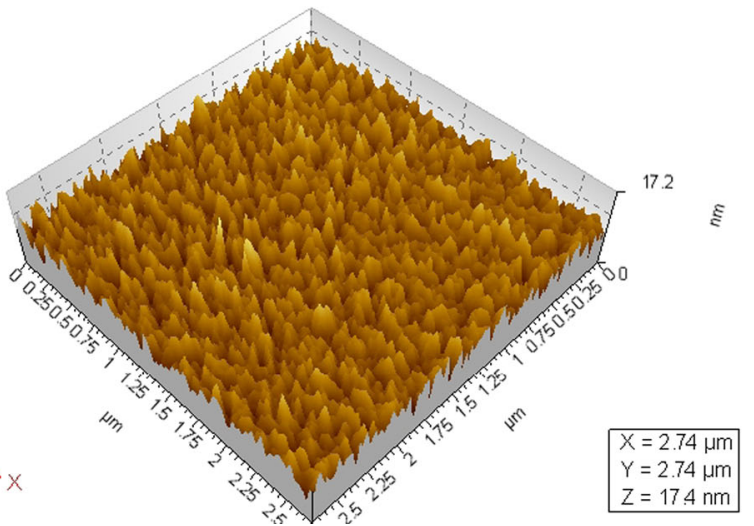

Fig. 4 AFM micrograph of synthesized silver nanoparticles from Malva sylvestris, a $2.5 \mu \mathrm{m}$ resolution studies 3- to 17-nm size, spherical shaped, polydispersed particles, $\mathbf{b} 3 \mathrm{D}$ image of AgNP analyzed by NOVA-TX software, and $\mathbf{c}$ histogram showing the particle size distribution
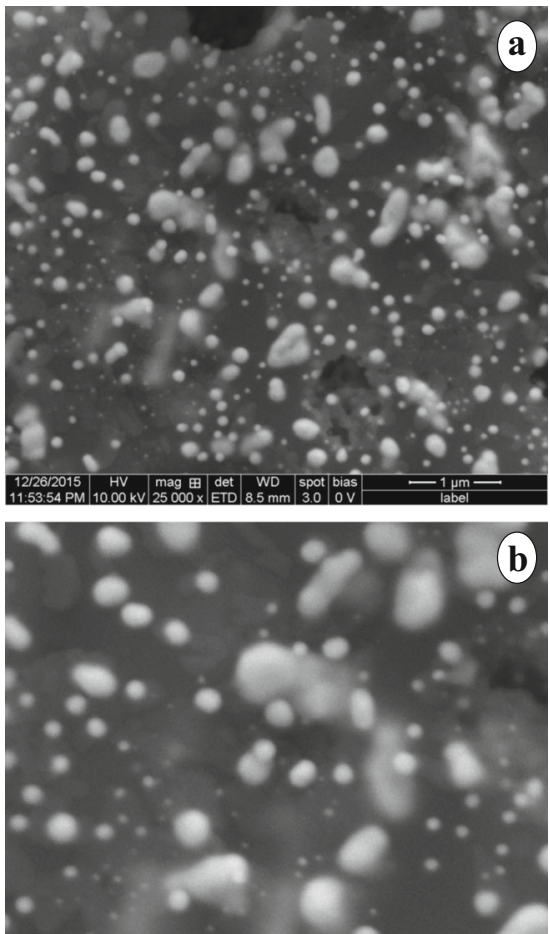

Fig. 5 Scanning electron microscopy (SEM) images of Malva sylvestris silver nanoparticles at different resolutions $(\mathbf{a} \times 25,000$ and $\mathbf{b} \times 50,000)$ synthesized AgNP exhibited a brown color, due to excitation of surface plasmon vibrations (Govindarajan and Benelli 2015). The surface plasmon resonance bands are influenced by size, shape, morphology, composition, and dielectric environment of AgNP. Previous research has shown that spherical AgNP contribute to the absorption band at around 400$480 \mathrm{~nm}$ in the UV-Vis spectrum (Shameli et al. 2012). These bands corresponded to that of AgNP, and the UV-Vis absorption spectrum showed broad surface plasmon resonance at $449 \mathrm{~nm}$ (Fig. 1b). The synthesized AgNP were stable in solution for at least 4 weeks after nanosynthesis.

The crystalline nature of AgNP was studied by XRD analysis (Fig. 2). XRD patterns confirmed the crystalline nature of synthesized AgNP. Four diffraction peaks were observed at 38.22, 44.37, 64.53, and 77.46 and represent the (111), (200), (220), and (311) reflections and the face-centered cubic structure of metallic silver, respectively. Similar phenomena were reported earlier (Govindarajan et al. 2015). For instance, AgNP fabricated using Trianthema decandra showed interplanar distance that corresponds to mixed phase of cubic and hexagonal structures (Geethalakshmi and Sarada 2010).

The FTIR spectrum of AgNP synthesized with M. sylvestris leaf extract is shown in Fig. 3. The peak at 


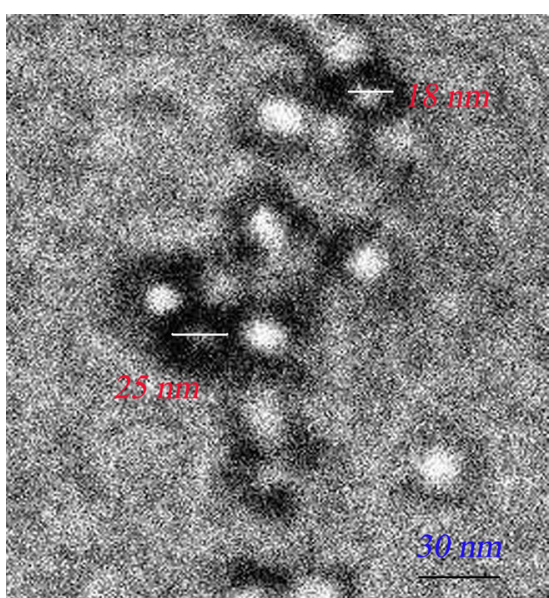

Fig. 6 TEM micrograph of silver nanoparticles synthesized using the Malva sylvestris aqueous extract

$2922 \mathrm{~cm}^{-1}$ could indicate carboxylic acid (Li et al. 2007). The $2855 \mathrm{~cm}^{-1}$ indicates the presence of methylene group $\left(\mathrm{CH}_{2}\right)$ next to $\mathrm{OH}$ or $\mathrm{NH}_{2}$ functional group. The band at $1383 \mathrm{~cm}^{-1}$ corresponds to $\mathrm{C}-\mathrm{C}$ stretching of aromatic amine. The peak at 1167 and $1117 \mathrm{~cm}^{-1}$ probably indicates the presence of $\mathrm{C}-\mathrm{O}$ stretching alcohols, carboxylic acids, esters, and ethers. The peak obtained at $855 \mathrm{~cm}^{-1}$ witnessed the bending vibrations of $\mathrm{C}-\mathrm{H}$ groups of phenyl rings. The peak near $683 \mathrm{~cm}^{-1}$ is assigned to $\mathrm{CH}$ out of plane bending vibrations of substituted ethylene systems $-\mathrm{CH}=\mathrm{CH}$ (Veerekumar et al. 2013). Overall, the rapid reduction of silver ions might be linked with the presence of water-soluble phytochemicals such as
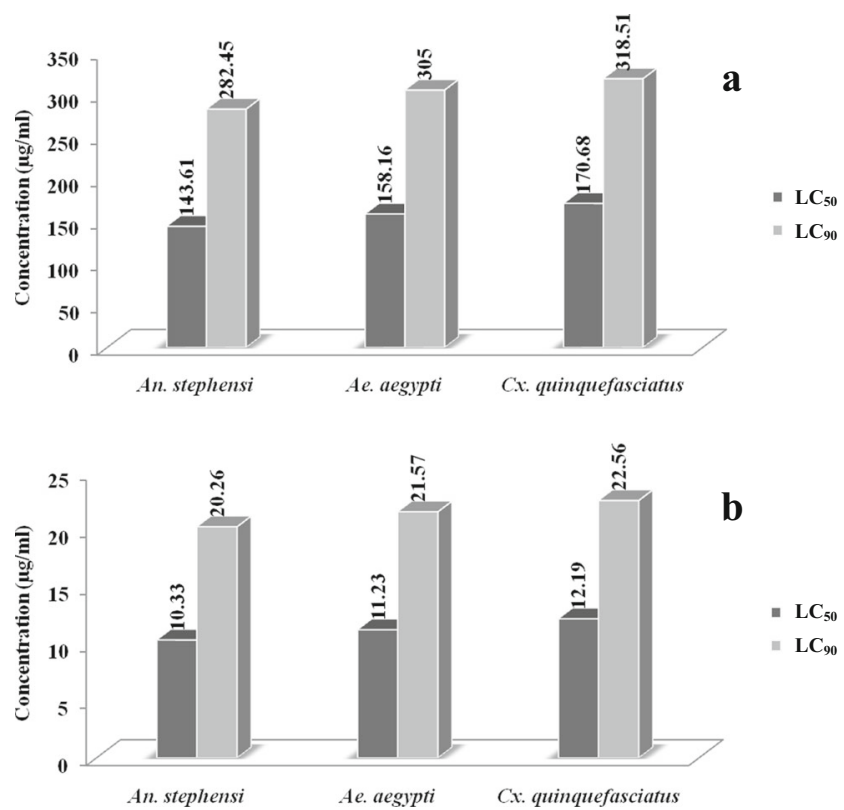

Fig. 7 Larvicidal activity of aqueous leaf extract (a) and silver nanoparticles (b) synthesized using the Malva sylvestris against the mosquito vectors Anopheles stephensi, Aedes aegypti, and Culex quinquefasciatus

flavones, quinones, and organic acids present in the leaf extract of M. sylvestris.

AFM is a primary tool for analyzing size, shape, and agglomeration pattern and offers visualizations of threedimensional views of the nanoparticles unlike the electron microscopes. It has an advantage over combination of high

Table 1 Larvicidal activity of Malva sylvestris aqueous leaf extract against the mosquito vectors Anopheles stephensi, Aedes aegypti, and Culex quinquefasciatus

\begin{tabular}{|c|c|c|c|c|c|c|c|}
\hline Mosquito species & $\begin{array}{l}\text { Concentration } \\
(\mu \mathrm{g} / \mathrm{mL})\end{array}$ & $\begin{array}{l}\text { Mortality } \\
(\%) \pm \mathrm{SD}^{\mathrm{a}}\end{array}$ & $\begin{array}{l}\mathrm{LC}_{50}(\mu \mathrm{g} / \mathrm{mL}) \\
(\mathrm{LCL}-\mathrm{UCL})\end{array}$ & $\begin{array}{l}\mathrm{LC}_{90}(\mu \mathrm{g} / \mathrm{mL}) \\
(\mathrm{LCL}-\mathrm{UCL})\end{array}$ & Slope & Regression equation & $\chi^{2}(d f)$ \\
\hline \multirow[t]{5}{*}{ An. stephensi } & 70 & $28.7 \pm 0.8$ & \multirow[t]{5}{*}{$143.61(127.25-158.09)$} & \multirow[t]{5}{*}{$282.45(262.00-309.27)$} & \multirow[t]{5}{*}{3.18} & \multirow[t]{5}{*}{$y=11.23+0.263 x$} & $3.613(4)$ \\
\hline & 140 & $46.5 \pm 0.6$ & & & & & n.s. \\
\hline & 210 & $68.3 \pm 0.6$ & & & & & \\
\hline & 280 & $89.6 \pm 0.4$ & & & & & \\
\hline & 350 & $99.2 \pm 0.6$ & & & & & \\
\hline \multirow[t]{5}{*}{ Ae. aegypti } & 70 & $25.5 \pm 1.2$ & \multirow[t]{5}{*}{$158.16(141.89-172.88)$} & \multirow[t]{5}{*}{$305.00(282.98-334.02)$} & \multirow[t]{5}{*}{2.88} & \multirow[t]{5}{*}{$y=6.41+0.268 x$} & $2.301(4)$ \\
\hline & 140 & $41.3 \pm 0.6$ & & & & & n.s. \\
\hline & 210 & $63.9 \pm 0.6$ & & & & & \\
\hline & 280 & $85.4 \pm 0.8$ & & & & & \\
\hline & 350 & $97.2 \pm 0.4$ & & & & & \\
\hline \multirow[t]{5}{*}{ Cx. quinquefasciatus } & 70 & $21.8 \pm 0.4$ & \multirow[t]{5}{*}{$170.68(155.00-185.24)$} & \multirow[t]{5}{*}{$318.51(295.85-348.36)$} & \multirow[t]{5}{*}{2.51} & \multirow[t]{5}{*}{$y=1.91+0.275 x$} & $2.035(4)$ \\
\hline & 140 & $38.6 \pm 0.6$ & & & & & n.s. \\
\hline & 210 & $59.2 \pm 0.4$ & & & & & \\
\hline & 280 & $82.3 \pm 0.4$ & & & & & \\
\hline & 350 & $96.1 \pm 0.8$ & & & & & \\
\hline
\end{tabular}

No mortality was observed in the control

$S D$ standard deviation, $L C_{50}$ lethal concentration that kills $50 \%$ of the exposed organisms, $L C_{90}$ lethal concentration that kills $90 \%$ of the exposed organisms, UCL $95 \%$ upper confidence limit, $L C L 95 \%$ lower confidence limit, $\chi^{2}$ chi square, $d f$ degrees of freedom, $n . s$. not significant $(\alpha=0.05)$

${ }^{\text {a }}$ Values are mean $\pm \mathrm{SD}$ of five replicates 
Table 2 Larvicidal activity of silver nanoparticles synthesized using the Malva sylvestris leaf extract against the mosquito vectors Anopheles stephensi, Aedes aegypti, and Culex quinquefasciatus

\begin{tabular}{|c|c|c|c|c|c|c|c|}
\hline Mosquito species & $\begin{array}{l}\text { Concentration } \\
(\mu \mathrm{g} / \mathrm{mL})\end{array}$ & $\begin{array}{l}\text { Mortality } \\
(\%) \pm \mathrm{SD}^{\mathrm{a}}\end{array}$ & $\begin{array}{l}\mathrm{LC}_{50}(\mu \mathrm{g} / \mathrm{mL}) \\
(\mathrm{LCL}-\mathrm{UCL})\end{array}$ & $\begin{array}{l}\mathrm{LC}_{90}(\mu \mathrm{g} / \mathrm{mL}) \\
(\mathrm{LCL}-\mathrm{UCL})\end{array}$ & Slope & Regression equation & $\chi^{2}(d f)$ \\
\hline \multirow[t]{5}{*}{ An. stephensi } & 5 & $27.3 \pm 1.2$ & \multirow[t]{5}{*}{$10.33(9.15-11.36)$} & \multirow[t]{5}{*}{$20.26(18.79-22.18)$} & \multirow[t]{5}{*}{3.14} & \multirow[t]{5}{*}{$y=10.95+3.686 x$} & $4.06(4)$ \\
\hline & 10 & $48.9 \pm 0.8$ & & & & & \\
\hline & 15 & $66.5 \pm 0.8$ & & & & & \\
\hline & 20 & $89.2 \pm 0.6$ & & & & & \\
\hline & 25 & $99.3 \pm 0.4$ & & & & & \\
\hline \multirow[t]{5}{*}{ Ae. aegypti } & 5 & $23.4 \pm 0.6$ & \multirow[t]{5}{*}{$11.23(10.08-12.27)$} & \multirow[t]{5}{*}{$21.57(20.02-23.59)$} & \multirow[t]{5}{*}{2.82} & \multirow[t]{5}{*}{$y=6.45+3.77 x$} & $2.326(4)$ \\
\hline & 10 & $45.6 \pm 0.4$ & & & & & n.s. \\
\hline & 15 & $62.3 \pm 0.4$ & & & & & \\
\hline & 20 & $86.5 \pm 1.2$ & & & & & \\
\hline & 25 & $97.2 \pm 0.8$ & & & & & \\
\hline \multirow[t]{5}{*}{ Cx. quinquefasciatus } & 5 & $19.6 \pm 0.6$ & \multirow[t]{5}{*}{$12.19(11.09-13.22)$} & \multirow[t]{5}{*}{$22.56(20.97-24.63)$} & \multirow[t]{5}{*}{2.43} & \multirow[t]{5}{*}{$y=1.43+3.886 x$} & $1.778(4)$ \\
\hline & 10 & $41.2 \pm 0.6$ & & & & & \\
\hline & 15 & $59.4 \pm 0.4$ & & & & & \\
\hline & 20 & $82.1 \pm 0.8$ & & & & & \\
\hline & 25 & $96.3 \pm 1.2$ & & & & & \\
\hline
\end{tabular}

No mortality was observed in the control

$S D$ standard deviation, $L C_{50}$ lethal concentration that kills $50 \%$ of the exposed organisms, $L C_{90}$ lethal concentration that kills $90 \%$ of the exposed organisms, $U C L 95 \%$ upper confidence limit, $L C L 95 \%$ lower confidence limit, $\chi^{2}$ chi square, $d f$ degrees of freedom, n.s. not significant $(\alpha=0.05)$

${ }^{\mathrm{a}}$ Values are mean $\pm \mathrm{SD}$ of five replicates

resolution samples, does not have to be conductive, and does not require the high-pressure vacuum conditions. The $2.5-\mu \mathrm{m}$ resolution studies of green-synthesized AgNP with AFM reveal that the particles are polydispersed, spherical in shape, having the size range from 3 to $17 \mathrm{~nm}$, and having no agglomeration observed between the particles (Fig. 4a). Raw data obtained from this AFM microscope is treated with a specially designed image processing software (NOVA-TX) to further exploit the 3D image of nanoparticles (Fig. 4b). The average particle size obtained from the corresponding diameter distribution was about $8 \mathrm{~nm}$ (Fig. 4c).

SEM analysis was performed in order to investigate the morphology and size distribution of AgNP (Fig. 5a, b). SEM showed that the morphology of AgNP is mostly spherical, in agreement with the shape of SPR band in the UV-vis spectrum. The average particle size measured from all the SEM images is around 25 to $50 \mathrm{~nm}$. Metallic AgNP generally show typical absorption peak approximately at $3 \mathrm{keV}$ due to surface plasmon resonance (Magudapatty et al. 2001). TEM micrograph confirms the presence of polydispersed AgNP, showing fine configuration of crystalline, spherical AgNP, with size ranging between 18 and $25 \mathrm{~nm}$ (Fig. 6) and mean size of $20 \mathrm{~nm}$. It was also noted that AgNP bound with thin layer of biomolecule coating on their surface which act as stabilizing agent; therefore, AgNP were polydispersed without direct contact and stable for long period of time (Vignesh et al. 2013).

Table 3 Biotoxicity of Malva sylvestris aqueous leaf extract against two non-target organisms sharing the same ecological niche of mosquito vectors

\begin{tabular}{|c|c|c|c|c|c|c|c|}
\hline $\begin{array}{l}\text { Non-target } \\
\text { organism }\end{array}$ & $\begin{array}{l}\text { Concentration } \\
(\mu \mathrm{g} / \mathrm{mL})\end{array}$ & $\begin{array}{l}\text { Mortality } \\
(\%) \pm \mathrm{SD}^{\mathrm{a}}\end{array}$ & $\begin{array}{l}\mathrm{LC}_{50}(\mu \mathrm{g} / \mathrm{mL}) \\
(\mathrm{LCL}-\mathrm{UCL})\end{array}$ & $\begin{array}{l}\mathrm{LC}_{90}(\mu \mathrm{g} / \mathrm{mL}) \\
(\mathrm{LCL}-\mathrm{UCL})\end{array}$ & Slope & $\begin{array}{l}\text { Regression } \\
\text { equation }\end{array}$ & $\chi^{2}(d f)$ \\
\hline D. indicus & $\begin{array}{l}4000 \\
8000 \\
12000 \\
16000 \\
20000\end{array}$ & $\begin{array}{l}26.8 \pm 0.8 \\
48.2 \pm 1.2 \\
67.4 \pm 1.2 \\
89.3 \pm 0.8 \\
100.0 \pm 0.0\end{array}$ & 8282.25 (7379.61-9086.64) & 15964.04 (14826.85-17450.54) & 2.87 & $y=10.09+0.005 x$ & $\begin{array}{l}4.926(4) \\
\text { n.s. }\end{array}$ \\
\hline G. affinis & $\begin{array}{l}5000 \\
10000 \\
15000 \\
20000 \\
25000\end{array}$ & $\begin{array}{l}27.5 \pm 0.6 \\
46.8 \pm 0.6 \\
67.4 \pm 0.8 \\
88.6 \pm 0.8 \\
97.2 \pm 0.6\end{array}$ & $10459.13(9234.44-11537.88)$ & 20958.91 (19416.23-22993.85) & 3.56 & $y=11.14+0.004 x$ & $\begin{array}{l}1.276(4) \\
\text { n.s. }\end{array}$ \\
\hline
\end{tabular}

No mortality was observed in the control

$S D$ standard deviation, $L C_{50}$ lethal concentration that kills $50 \%$ of the exposed organisms, $L C_{90}$ lethal concentration that kills $90 \%$ of the exposed organisms, UCL $95 \%$ upper confidence limit, $L C L 95 \%$ lower confidence limit, $\chi^{2}$ chi square, $d f$ degrees of freedom, $n . s$. not significant $(\alpha=0.05)$

${ }^{\mathrm{a}}$ Values are mean $\pm \mathrm{SD}$ of five replicates 
Table 4 Biotoxicity of silver nanoparticles synthesized using the Malva sylvestris leaf extract against two non-target organisms sharing the same ecological niche of mosquito vectors

\begin{tabular}{|c|c|c|c|c|c|c|c|}
\hline $\begin{array}{l}\text { Non-target } \\
\text { organism }\end{array}$ & $\begin{array}{l}\text { Concentration } \\
(\mu \mathrm{g} / \mathrm{mL})\end{array}$ & $\begin{array}{l}\text { Mortality } \\
(\%) \pm \mathrm{SD}^{\mathrm{a}}\end{array}$ & $\begin{array}{l}\mathrm{LC}_{50}(\mu \mathrm{g} / \mathrm{mL}) \\
(\mathrm{LCL}-\mathrm{UCL})\end{array}$ & $\begin{array}{l}\mathrm{LC}_{90}(\mu \mathrm{g} / \mathrm{mL}) \\
(\mathrm{LCL}-\mathrm{UCL})\end{array}$ & Slope & $\begin{array}{l}\text { Regression } \\
\text { equation }\end{array}$ & $\chi^{2}(d f)$ \\
\hline D. indicus & $\begin{array}{l}400 \\
800 \\
1200 \\
1600 \\
2000\end{array}$ & $\begin{array}{l}29.4 \pm 1.2 \\
47.3 \pm 0.6 \\
68.5 \pm 0.4 \\
88.4 \pm 0.6 \\
100.0 \pm 0.0\end{array}$ & $813.16(718.55-896.50)$ & $1610.57(1493.10-1765.02)$ & 3.31 & $y=12.03+0.046 x$ & $\begin{array}{l}5.273(4) \\
\text { n.s. }\end{array}$ \\
\hline G. affinis & $\begin{array}{l}400 \\
800 \\
1200 \\
1600 \\
2000\end{array}$ & $\begin{array}{l}26.8 \pm 0.6 \\
48.2 \pm 0.6 \\
66.5 \pm 0.4 \\
89.3 \pm 0.8 \\
97.4 \pm 1.2\end{array}$ & $1044.52(923.55-1151.24)$ & $2080.06(1927.94-2280.32)$ & 3.42 & $y=10.95+0.036 x$ & $\begin{array}{l}1.733(4) \\
\text { n.s. }\end{array}$ \\
\hline
\end{tabular}

No mortality was observed in the control

$S D$ standard deviation, $L C_{50}$ lethal concentration that kills $50 \%$ of the exposed organisms, $L C_{90}$ lethal concentration that kills $90 \%$ of the exposed organisms, UCL $95 \%$ upper confidence limit, $L C L 95 \%$ lower confidence limit, $\chi^{2}$ chi square, $d f$ degrees of freedom, $n . s$. not significant $(\alpha=0.05)$

${ }^{\mathrm{a}}$ Values are mean $\pm \mathrm{SD}$ of five replicates

\section{Acute toxicity against mosquito larvae}

Both the M. sylvestris leaf extract and AgNP showed dosedependent larvicidal effect against all tested mosquito species (Table 1; Fig. 7a). Compared to the leaf aqueous extract, AgNP showed higher toxicity against A. stephensi, $A$. aegypti, and $C$. quinquefasciatus with $\mathrm{LC}_{50}$ values of $10.33,11.23$, and $12.19 \mu \mathrm{g} / \mathrm{mL}$, respectively (Table 2; Fig. 7b). Furthermore, AgNP showed enhanced larvicidal effect even at lower concentrations compared to plant derivatives alone, which denotes that AgNP potentially
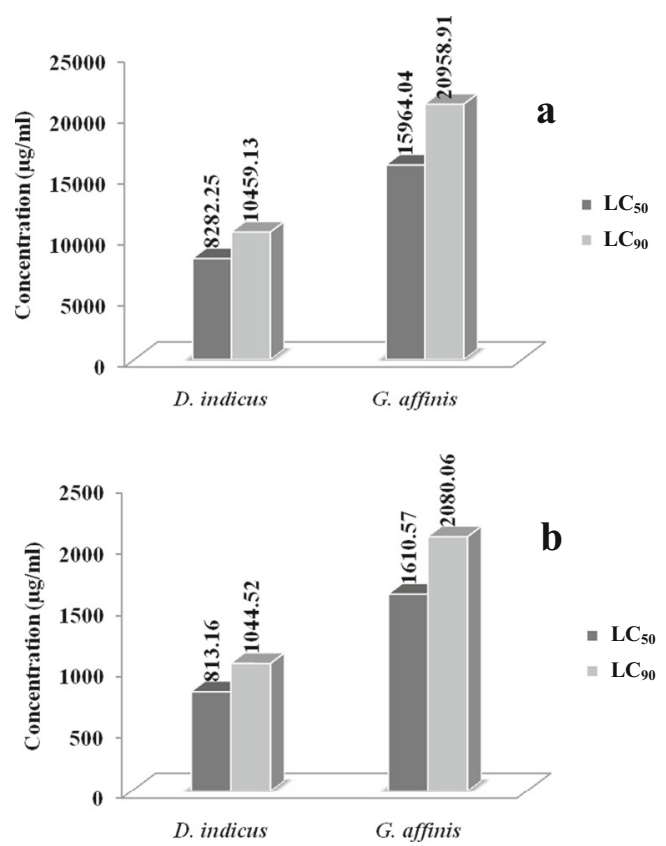

Fig. 8 Biotoxicity of aqueous leaf extract (a) and silver nanoparticles (b) synthesized using the Malva sylvestris against two non-target organisms sharing the same ecological niche of mosquito vectors increases the bioactivity of plant products. Recently, a growing number of plants have been explored for the green synthesis of mosquitocidal AgNP, and it has been showed that the combination of nanoparticles with bioactive principles bestows improved efficiency (Benelli 2016; Haldar et al. 2013). The present study implicated that the percentage of mosquito larvicidal mortality increased by many folds with the addition of bio-stabilized AgNP. Similarly, Muthukumaran et al. (2015b) recently focused on the potential of Gmelina asiatica-mediated synthesis of AgNP against A. stephensi, A. aegypti, and C. quinquefasciatus, obtaining higher $\mathrm{LC}_{50}$ values (i.e., 22.44, 25.77, and $27.83 \mu \mathrm{g} / \mathrm{mL}$, respectively). Murugan et al. (2015) showed that low doses (1 ppm) of Cymbopogon citratus-synthesized gold nanoparticles control malaria and dengue vectors and boost early instar mosquito larvae predation by copepods in a nanoparticle-contaminated aquatic environment. Concerning the mechanism(s) of action, the observed larvicidal activity may be attributed to the interaction between silver nanoparticles and the extracellular lipoprotein matrix. This interaction increases the permeability of the plasma membrane of cells. Additionally, an interaction between AgNP and the sulfur-containing proteins or phosphorous containing compound leads to denaturation of organelles and enzymes and reduces ATP synthesis which finally causes the loss of the cellular function and cell death (Sap-Iam et al. 2010; Sondi and Salopek-Sondi 2004).

\section{Biotoxicity on non-target organisms}

The biotoxicity of $M$. sylvestris aqueous extract and greensynthesized AgNP was evaluated on non-target organisms $D$. indicus and G. affinis. Toxicity treatments achieved negligible toxicity against $D$. indicus and $G$. affinis, with $\mathrm{LC}_{50}$ values 
Table 5 Suitability index of different non-target organisms over young instars of Anopheles stephensi, Aedes aegypti, and Culex quinquefasciatus exposed to Malva sylvestris aqueous leaf extract and green-synthesized silver nanoparticles

\begin{tabular}{lllll}
\hline Treatment & Non-target organism & An. stephensi & Ae. aegypti & Cx. quinquefasciatus \\
\hline Aqueous leaf extract & Diplonychus indicus & 57.67 & 52.36 & 48.52 \\
& Gambusia affinis & 72.83 & 66.13 & 61.27 \\
Silver nanoparticles & Diplonychus indicus & 78.71 & 72.40 & 66.70 \\
& Gambusia affinis & 101.11 & 93.01 & 85.68 \\
\hline
\end{tabular}

ranging from 813.16 to $10,459.13 \mu \mathrm{g} / \mathrm{mL}$ (Tables 3 and 4 ; Fig. 8a, b). Focal observations highlighted that longevity and swimming activity of the study species were not altered for a week after testing. SI indicated that M. sylvestris-fabricated AgNP were less toxic to the non-target organism tested if compared to the targeted mosquito larval populations (Table 5). Nowadays, moderate knowledge is available about the acute toxicity of mosquitocidal nanoparticles toward non-target aquatic species (Benelli 2016). Pergularia rubra- and Pergularia daemia-synthesized AgNP did not exhibit any evident toxicity effect against Poecilia reticulata fishes, after $48 \mathrm{~h}$ of exposure to $\mathrm{LC}_{50}$ and $\mathrm{LC}_{90}$ values calculated on IV instar larvae of A. aegypti and A. stephensi (Patil et al. 2012b). Haldar et al. (2013) did not detect toxicity of AgNP produced using dried green fruits of $D$. roxburghii against $P$. reticulata, after 48-h exposure to $\mathrm{LC}_{50}$ of IV instar larvae of $A$. stephensi and C. quinquefasciatus. Rawani et al. (2013) showed that mosquitocidal AgNP synthesized using Solanum nigrum berry extracts were not toxic against two mosquito predators, Toxorhynchites larvae and Diplonychus annulatum, and Chironomus circumdatus larvae, exposed to lethal concentrations of dry nanoparticles calculated on A. stephensi and C. quinquefasciatus larvae. AgNP biosynthesized using the 2, 7.bis[2-[diethylamino]-ethoxy]fluorence isolate from the Melia azedarach leaves did not show acute toxicity against Mesocyclops pehpeiensis copepods (Ramanibai and Velayutham 2015). Interestingly, the exposure to extremely low doses (e.g., 1 ppm) of green-synthesized AgNP did not negatively affect the predation efficiency of a number of mosquito predators of relevance for mosquito control (Benelli 2016; Murugan et al. 2015). It has been hypothesized that low doses of plant-synthesized metal nanoparticles may reduce the motility of mosquito larvae, enhancing predation of odonate nymphs and other mosquito natural enemies (Benelli 2016).

\section{Conclusions}

The plant-mediated synthesis of the silver nanoparticles is one-pot, eco-friendly, and cost-effective. In the present study, AgNP were rapidly biosynthesized at room temperature using a cheap M. sylvestris leaf extract. Bio-reduced silver nanocrystals were polydispersed and stable in solution for at least 4 weeks. AgNP have excellent anti-mosquito larvicidal activity against third instar larvae of three important mosquito vectors, with $\mathrm{LC}_{50}$ values ranging from 10.33 to $12.19 \mu \mathrm{g} / \mathrm{mL}$. Overall, this $M$. sylvestris-based route of nanosynthesis may be considered for the development of newer and safer mosquito larvicides.

Acknowledgments The authors would like to thank the Professor and Head of the Department of Zoology, Annamalai University, for the laboratory facilities provided. The authors would also like to acknowledge the cooperation of staff members of the VCRC (ICMR), Pondicherry, and thank Dr. S. Ramesh, Professor and Head, Veterinary College, Vepery, Chennai, for TEM analysis.

Compliance with ethical standards All applicable international and national guidelines for the care and use of animals were followed. All procedures performed in studies involving animals were in accordance with the ethical standards of the institution or practice at which the studies were conducted.

Conflict of interest The authors declare no conflicts of interest. G. Benelli is an Editorial Board Member of Parasitology Research. This does not alter the authors' adherence to all the Parasitology Research policies on sharing data and materials.

\section{References}

Barros L, Carvalho AM, Ferreira IC (2010) Leaves, flowers, immature fruits and leafy flowered stems of Malva sylvestris: a comparative study of the nutraceutical potential and composition. Food Chem Toxicol 48:1466-1472

Benelli G (2015a) Plant-borne ovicides in the fight against mosquito vectors of medical and veterinary importance: a systematic review. Parasitol Res 114:3201-3212

Benelli G (2015b) Research in mosquito control: current challenges for a brighter future. Parasitol Res 114:2801-2805

Benelli G (2016) Plant-mediated biosynthesis of nanoparticles as an emerging tool against mosquitoes of medical and veterinary importance: a review. Parasitol Res. doi:10.1007/s00436-015-4800-9

Benelli G, Mehlhorn H (2016) Declining malaria, rising dengue and Zika virus: insights for mosquito vector control. Parasitol Res. doi:10. 1007/s00436-016-4971-z

Benelli G, Lo Iacono A, Canale A, Mehlhorn H (2016) Mosquito vectors and the spread of cancer: an overlooked connection? Parasitol Res. doi:10.1007/s00436-016-5037-y

Billeter M, Meier B, Sticher O (1991) 8-hydroxyflavonoid glucuronides from Malva sylvestris. Phytochem 30:987-990 
Deo PG, Hasan SB, Majumdar SK (1988) Toxicity and suitability of some insecticides for household use. Int Pest Control 30:118-129

Finney DJ (1971) Probit analysis. Cambridge University Press, London, pp 68-72

Gardea-Torresdey JL, Parsons JG, Gomez E, Videa-Peralta J, Troiani HE, Santiago P (2002) Formation and growth of Au nanoparticles inside live alfalfa plants. Nano Lett 2:397-401

Geethalakshmi R, Sarada DVL (2010) Trianthema decandra L: a review on its phytochemical and pharmacological profile. Int J Eng Sci Technol 2:976-979

Govindarajan M, Benelli G (2015) Facile biosynthesis of silver nanoparticles using Barleria cristata: mosquitocidal potential and biotoxicity on three non-target aquatic organisms. Parasitol Res. doi:10.1007/s00436-015-4817-0

Govindarajan M, Rajeswary M, Hoti SL, Bhattacharyya A, Benelli G (2015) Eugenol, $\alpha$-caryophyllene from Plectranthus barbatus essential oil as eco-friendly larvicides against malaria, dengue and Japanrese encephalitis mosquito vectors. Parasitol Res. doi:10. 1007/s00436-015-4809-0

Haldar KM, Haldar B, Chandra G (2013) Fabrication, characterization and mosquito larvicidal bioassay of silver nanoparticles synthesized from aqueous fruit extract of putranjiva, Drypetes roxburghii (Wall.). Parasitol Res 112:1451-1459

Howard AF, Zhou G, Omlin FX (2007) Malaria mosquito control using edible fish in western Kenya: preliminary findings of a controlled study. BMC Public Health 7:199

Huang J, Li Q, Sun D (2007) Biosynthesis of silver and gold nanoparticles by novel sundried Cinnamomum camphora leaf. Nanotechnology 18(105104):1-11

Kalimuthu K, Babu RS, Venkataraman D, Bilal M, Gurunathan S (2008) Biosynthesis of silver nanocrystals by Bacillus licheniformis. Colloid Surface B 65:150-153

Lee HJ, Yeo SY, Jeong SH (2003) Antibacterial effect of nanosized silver colloidal solution on textile fabrics. J Mater Sci 38:2199-2204

Li S, Shen Y, Xie A, Yu X, Qiu L, Zhang L, Zhang Q (2007) Green synthesis of silver nanoparticles using Capsicum annuum L. extract. Green Chem 9:852-858

Magudapatty P, Gangopadhyayransm P, Panigrahi BK, Nair KGM, Dhara S (2001) Electrical transport studies of Ag nanoparticles embedded in glass matrix. Physica B 299:142-146

Murugan K, Benelli G, Panneerselvam C, Subramaniam J, Jeyalalitha T, Dinesh D, Nicoletti M, Hwang JS, Suresh U, Madhiyazhagan P (2015) Cymbopogon citratus-synthesized gold nanoparticles boost the predation efficiency of copepod Mesocyclops aspericornis against malaria and dengue mosquitoes. Exp Parasitol 153:129-138

Murugan K, Nataraj D, Madhiyazhagan P, Sujitha V, Chandramohan B, Panneerselvam C, Dinesh D, Chandirasekar R, Kovendan K, Suresh U, Subramaniam J, Paulpandi M, Vadivalagan C, Rajaganesh R, Wei H, Syuhei B, Aziz AT, Saleh Alsalhi M, Devanesan S, Nicoletti M, Canale A, Benelli G (2016a) Carbon and silver nanoparticles in the fight against the filariasis vector Culex quinquefasciatus: genotoxicity and impact on behavioral traits of non-target aquatic organisms. Parasitol Res 115:1071-1083

Murugan K, Dinesh D, Kavithaa K, Paulpandi M, Ponraj T, Saleh Alsalhi M, Devanesan S, Subramaniam J, Rajaganesh R, Wei H, Suresh K, Nicoletti M, Benelli G (2016b) Hydrothermal synthesis of titanium dioxide nanoparticles: mosquitocidal potential and anticancer activity on human breast cancer cells (MCF-7). Parasitol Res 115:10851096

Murugan K, Panneerselvam C, Samidoss CM, Madhiyazhagan P, Suresh U, Roni M, Chandramohan B, Subramaniam J, Dinesh D, Rajaganesh R, Paulpandi M, Wei H, Aziz AT, Saleh Alsalhi M, Devanesan S, Nicoletti M, Pavela R, Canale A, Benelli G (2016c) In vivo and in vitro effectiveness of Azadirachta indica-synthesized silver nanocrystals against Plasmodium berghei and Plasmodium falciparum, and their potential against malaria mosquitoes. Res Vet Sci 106:14-22

Muthukumaran U, Govindarajan M, Rajeswary M (2015a) Synthesis and characterization of silver nanoparticles using Gmelina asiatica leaf extract against filariasis, dengue, and malaria vector mosquitoes. Parasitol Res 114:1817-1827

Muthukumaran U, Govindarajan M, Rajeswary M (2015b) Mosquito larvicidal potential of silver nanoparticles synthesized using Chomelia asiatica (Rubiaceae) against Anopheles stephensi, Aedes aegypti, and Culex quinquefasciatus (Diptera: Culicidae). Parasitol Res 114:989-999

Patil CD, Borase HP, Patil SV, Salunkhe RB, Salunke BK (2012a) Larvicidal activity of silver nanoparticles synthesized using Pergularia daemia plant latex against Aedes aegypti and Anopheles stephensi and nontarget fish Poecillia reticulate. Parasitol Res 111:555-562

Patil CD, Patil SV, Borase HP, Salunke BK, Salunkhe RB (2012b) Larvicidal activity of silver nanoparticles synthesized using Plumeria rubra plant latex against Aedes aegypti and Anopheles stephensi. Parasitol Res 110:1815-1822

Pavela R (2015a) Essential oils for the development of eco-friendly mosquito larvicides: a review. Ind Crop Prod 76:174-187

Pavela R (2015b) Larvicidal property of essential oils against Culex quinquefasciatus Say (Diptera: Culicidae). Ind Crop Prod 30:311315

Pirbalouti AG, Azizi S, Koohpayeh A, Hamedi B (2010) Wound healing activity of Malva sylvestris and Punica granatum in alloxan-induced diabetic rats. Acta Pol Pharm 67:511-516

Raghvendra K (2002) Chemical insecticides in malaria vector control in India. ICMR Bull 32

Ramanibai R, Velayutham K (2015) Bioactive compound synthesis of Ag nanoparticles from leaves of Melia azedarach and its control for mosquito larvae. Res Vet Sci 98:82-88

Rawani A, Ghosh A, Chandra G (2013) Mosquito larvicidal and antimicrobial activity of synthesized nano-crystalline silver particles using leaves and green berry extract of Solanum nigrum L. (Solanaceae: Solanales). Acta Trop 128:613-622

Salam H, Rajiv A, Kamaraj P, Jagadeeswaran M, Sangeetha P, Gunalan Sivaraj R (2012) Plants: green route for nanoparticle synthesis. Int Res J Biol Sci 1:85-90

Sap-Iam N, Homklinchan C, Larpudomlert R, Warisnoicharoen W, Sereemaspun A, Dubas S (2010) UV irradiation-induced silver nanoparticles as mosquito larvicides. J Appl Sci (Faisalabad) 10: 3132-3136

Sarwar M, Ahmad N, Toufiq M (2009) Host plant resistance relationships in chickpea (Cicer arietinum L.) against gram pod borer (Helicoverpa armigera Hubner). Pak J Bot 41:3047-3052

Shameli K, Ahmad MB, Jazayeri SD, Shabanzadeh P, Sangpour P, Jahangirian H, Gharayebi Y (2012) Investigation of antibacterial properties silver nanoparticles prepared via green method. Chem Cent J 6:73

Sivagnaname N, Kalyanasundaram M (2004) Laboratory evaluation of methanolic extract of Atlantia monophylla (Family: Rutaceae) against immature stages of mosquitoes and non-target organisms. Mem Inst Oswaldo Cruz Rio de Janeiro 99:115-118

Smitha SL, Nissamudeen KM, Philip D, Gopchandran KG (2008) Studies on surface plasmon resonance and photoluminescence of silver nanoparticles. Spectrochim Acta A 71:186-190

Sondi I, Salopek-Sondi B (2004) Silver nanoparticles as antimicrobial agent: a case study on E. coli as a model for Gram-negative bacteria. J Colloid Interface Sci 275:177-182

Tomoda M, Gonda R, Shimizu N, Yamada H (1989) Plant mucilages. XLII. An anti-complementary mucilage from the leaves of Malva sylvestris var. mauritiana. Chem Pharm Bull 37:3029-3032

Veerakumar K, Govindarajan M, Rajeswary M, Muthukumaran U (2014a) Low-cost and eco-friendly green synthesis of silver 
nanoparticles using Feronia elephantum (Rutaceae) against Culex quinquefasciatus, Anopheles stephensi, and Aedes aegypti (Diptera: Culicidae). Parasitol Res 113:1775-1785

Veerakumar K, Govindarajan M, Rajeswary M, Muthukumaran U (2014b) Mosquito larvicidal properties of silver nanoparticles synthesized using Heliotropium indicum (Boraginaceae) against Aedes aegypti, Anopheles stephensi, and Culex quinquefasciatus (Diptera: Culicidae). Parasitol Res 113: 2363-2373

Veerekumar K, Govindarajan M, Rajeswary M (2013) Green synthesis of silver nanoparticles using Sida acuta (Malvaceae) leaf extract against Culex quinquefasciatus, Aedes aegypti and Anopheles stephensi (Diptera: Culicidae). Parasitol Res 112:4073-4085

Vignesh V, Anbarasi KF, Karthikeyeni S, Sathiyanarayanan G, Subramaniana P, Thirumurugan R (2013) A superficial phytoassisted synthesis of silver nanoparticles and their assessment on hematological and biochemical parameters in Labeo rohita (Hamilton, 1822). Colloids Surf A 439:184-192

World Health Organization (2005) Guidelines for laboratory and field testing of mosquito larvicides. Communicable disease control, prevention and eradication, WHO pesticide evaluation scheme. WHO, Geneva, WHO/CDS/WHOPES/GCDPP/1.3 